\title{
Emulating Odontolegal Practice: A Paradigm Shift in the Dental Practice Laying More Emphasis on Dental Records-A Perspective and Contemporary Study with a Reality Check
}

\author{
Bhavna Kaul ${ }^{1}$, Shivam Gupta ${ }^{2}$, Vasu Vaid ${ }^{3}$, Sambhav Kaul ${ }^{4}$
}

\begin{abstract}
Aim: This study was conducted to evaluate the knowledge and the awareness on odontolegal practice with more emphasis on significance of maintaining dental records by the oral health professionals.

Materials and methods: A cross-sectional study was carried out among 120 dental practitioners of Jammu and Kashmir, Himachal Pradesh, Delhi, Punjab, Gujarat, and Odisha. A questionnaire was designed to assess their practice and knowledge regarding the importance of maintenance of dental records and the knowledge about dental jurisprudence. Total 120 questionnaire samples were distributed among dental health professionals, and the data obtained were studied and formulated for significance of dental records.

Results: Feedback obtained was then analyzed. Seventy percentage of the dentists are not maintaining clinical records of their patients and $20 \%$ of the dentists acknowledged that they are not keeping or maintaining dental records like X-rays and cast models of their patients. Eighty percentage of dentists were not known to the ethical importance of dental record, i.e., for how long they have to maintain records of their patients and other details.

Conclusion: This study concludes that the oral health professionals lacked the knowledge and awareness about odontolegal aspects and the significance of maintaining dental records. It was observed that there was insufficient knowledge about medicolegal systems and there is a need to bring awareness and knowledge of the same in the dental fraternity.

Clinical significance: With the increasing use of medical insurance and subsequently mediclaims, negligence suits, scientific evaluation, and research purposes, and health planning, etc., the "dental records itself have evolved as a separate science and therefore needs to be considered in the curriculum for dental students as this would introduce the concept for application in their future practice, thus avoiding legal complications in the future."
\end{abstract}

Keywords: Consumer Protection Act, Dental records, Forensic odontology, Law, Medical jurisprudence.

International Journal of Clinical Pediatric Dentistry (2020): 10.5005/jp-journals-10005-1755

\section{INTRODUCTION}

A document that comprises information about the past serving as an evidence, especially an account kept in writing or some other permanent form is known as a record. These records can be used in research, administrative, financial, quality assurance, forensic, and medicolegal issues. A dental record can be explained as the detailed document comprising of a chief complaint, history of the present and past illnesses, clinical examination, diagnosis, treatment planning, and the management of a patient. ${ }^{1}$ It summarizes all the information regarding provision of dental care services, which includes patient and business records including billing, claims forms, laboratory charge, scheduling, and drug records, etc.

Dental practitioners must be aware of the legal elements, as there are greater possibilities of dentists encountering medicolegal cases, particularly in the context of patient empowerment and increased desire for improved esthetics. The important application of maintaining dental records supports in identification of human remains through dental records, resolving malpractice issues, odontolegal investigation, and providing assistance at the crime scene, in cases of any suspected abuse. To present forensic dental evidence, an expert on the basis of dental records can present scientific evidence and their expert testimony in the court of law. The dilemma always remains as to how much a dentist in India knows about the importance of dental records and its implication in the court of justice. This article is an attempt to extract knowledge for \begin{tabular}{l}
\hline \hline Department of Pediatric and Preventive Dentistry, Indira Gandhi \\
Government Dental College, Jammu, Jammu and Kashmir, India \\
${ }^{2}$ Department of Forensic Odontology, Indian Dental Association, \\
Mumbai, Maharashtra, India \\
${ }^{3}$ Department of Forensic Odontology, Gujarat Forensic Sciences \\
University, Gandhinagar, Gujarat, India \\
${ }^{4}$ Department of Dentistry, Govt Hospital Sarwal, Jammu, Jammu and \\
Kashmir, India \\
Corresponding Author: Bhavna Kaul, Department of Pediatric and \\
Preventive Dentistry, Indira Gandhi Government Dental College, \\
Jammu, Jammu and Kashmir, India, Phone: +91 9419122288, e-mail: \\
drbhavnakaul@yahoo.com \\
How to cite this article: Kaul B, Gupta S, Vaid V, et al. Emulating \\
Odontolegal Practice: A Paradigm Shift in the Dental Practice Laying \\
More Emphasis on Dental Records-A Perspective and Contemporary \\
Study with a Reality Check. Int J Clin Pediatr Dent 2020;13(3):217-220. \\
Source of support: Nil \\
Conflict of interest: None
\end{tabular}

the same from dental practitioners. Records serve as an important adjunct in the lawsuit. Written record, comprising of medical and dental history, treatment records, radiographs, photographs, casts, and patient models are the various types of dental record that need to be stored. ${ }^{1-5}$ Keeping the above requirement as the baseline, 
this study was conducted to assess, analyze the knowledge, and the awareness among oral health professionals in India about odontolegal practice.

\section{Materials and Methods}

- Oral health professionals in India.

- Formulation of questionnaire.

- Feedback collection.

The questionnaire was formulated keeping the practising dental practitioners in mind who keep coming across various dental cases. A cross-sectional study was carried out among 120 dental practitioners of Jammu and Kashmir, Himachal Pradesh, Delhi, Punjab, Gujarat, and Odisha. The questionnaire was designed to assess their practice and knowledge on the following matters:

- Awareness regarding dental records.

- Knowledge about dental jurisprudence and ethical dentistry.

A consent was prepared and distributed among voluntary dental practitioners where they were taken into confidence that their identity will not be revealed and their responses will remain confidential and anonymous. Only the researchers will know their individual answers to this questionnaire. The registration number of the dental practitioners was taken in the form of consent instead of their names.

Questionnaire Used in the Study Stepwise Step to Deduce the Knowledge of Dental Jurisprudence with More Emphasis on Dental Records:

1. How long have you been practising?
a. 1-3 years
Answer:
b. $4-8$ years
c. 8-12 years
d. More than 12 years

2. What are the number of patients you come across in a day?
a. $<10$
Answer:
b. $>10$
c. $<20$
d. $>20$

3. Whether all the cases you are coming across are of pathological importance?
a. Yes
Answer:
b. No

4. If no, mention the various other factors or causes, such as, accident and victim of physical offences/violence, etc.

Answer:

5. Have you come across patients with specific injuries?
a. Yes
Answer:
b. No

6. If so, have you noted them or maintained in your dental records?
a. Yes
Answer:
b. No

7. Do you maintain the extensive (clinical and other history) records of your patients?
a. Yes
Answer:
b. No

8. Do you keep and maintain records of your patient's history, $\mathrm{X}$-rays, and models, etc.?
a. Yes
Answer:
b. No

9. If yes, for how long you would be maintaining records of your patients?
a. 3 years
Answer:
b. 3-5 years
c. 5-10 years
d. More than 10 years

10. Are you aware of the importance of maintaining dental records for identification of the crime suspects and the deceased?
a. Yes
Answer:
b. No

11. Whether you have come across the patients who have been previously treated by other dentist?
a. Yes
Answer:
b. No

12. If so, whether those patients have proper medical/dental record from the previous practitioner?
a. Yes
Answer:
b. No

13. Do you think maintaining records is necessary for every visit/ treatment provided at your clinic/practice?
a. Yes
Answer:
b. No

14. Are you aware that a copy of treatment record should be given to patient, if asked for?
a. Yes
Answer:
b. No

15. Are you aware that you can present an expert testimony in the court supported by dental records as an evidence?
a. Yes
Answer:
b. No

16. Are you aware of any course or have you attended any workshop related to medicolegal issues?
a. Yes
Answer:
b. No

17. Do you know what consumer protection act is?
a. Yes
Answer:
b. No 
18. Do you know the legal procedures to tackle consumer protection act?
a. Yes
Answer:
b. No

19. Do you think a dentist is having all knowledge of medical jurisprudence?
a. Yes
Answer:
b. No

20. If no, do you think now it is important to have knowledge about medical/dental jurisprudence?
a. Yes
Answer:
b. No

21. If yes, specify how in your own words.

Answer:

\section{Results}

As per the findings (Table 1), it has been seen that most of the dentists who were involved in the study are working from last 4-8 years as general practitioners and they are coming across minimum 10 patients a day. Most of the patients, they are coming across are of pathological and esthetical importance. Apart from these, some have mentioned the various other factors, such as, accident and violence. According to the study, most of the dentists were able to see specific injuries and they have also noted down in their history but not to record. Seventy percentage of the dentists are not maintaining clinical records of their patients and $20 \%$ of the dentists agreed that they are not keeping and maintaining dental records like $X$-rays and cast models of their patients. Eighty percentage of dentists were not known to the ethical importance of dental record like for how long they have to maintain records of their patient. Very few were aware of maintaining dental records which serve as an important identification tool in cases of the crime suspects or deceased individual. It has been observed by the dental practitioners that mostly patients who have been previously treated by other dentists also lacked their dental records as these were also not properly maintained by the previous dentists. As they were not aware of the importance of maintaining the dental records and so they never even felt the need of doing so. It has also been seen that most of the dentists are not giving the treatment records of their patients to them. As most of the dentists are not known to medical jurisprudence, they are not aware of the fact that they can present an expert testimony in the court of law supported by dental record as an evidence. ${ }^{4}$ They have not attended any course or training in their entire career and that is the main reason they do not know medical jurisprudence and its importance in their practice. It has been revealed by themselves that they have not gone through any of the odontolegal case till now as they were not aware of importance of medical jurisprudence. Most of the dental practitioners were willing to acquire knowledge and they have suggested that a dental graduate while studying should thoroughly go through odontolegal case with the importance of dental ethics and significance of maintaining dental records.
Table 1: Feedback analysis

\begin{tabular}{|c|c|c|c|c|}
\hline \multirow[b]{2}{*}{ S. no } & \multirow[b]{2}{*}{ Questions } & \multicolumn{3}{|c|}{ Response } \\
\hline & & Yes (\%) & No (\%) & None (\%) \\
\hline 1 & $\begin{array}{l}\text { Whether all the cases you } \\
\text { are coming across are of } \\
\text { pathological importance? }\end{array}$ & 63 & 57 & \\
\hline 2 & $\begin{array}{l}\text { Have you come across } \\
\text { patients with specific } \\
\text { injuries? }\end{array}$ & 76 & 18 & 6 \\
\hline 3 & $\begin{array}{l}\text { If so, have you noted them } \\
\text { or maintained in your } \\
\text { dental records? }\end{array}$ & 8 & 86 & 6 \\
\hline 4. & $\begin{array}{l}\text { Do you maintain the } \\
\text { extensive (clinical and } \\
\text { other history) records of } \\
\text { your patients? }\end{array}$ & 7 & 93 & \\
\hline 5 & $\begin{array}{l}\text { Do you keep and maintain } \\
\text { records of your patient's } \\
\text { history, X-rays, and models, } \\
\text { etc.? }\end{array}$ & 7 & 93 & \\
\hline 6 & $\begin{array}{l}\text { Are you aware of the } \\
\text { importance of maintaining } \\
\text { dental records for } \\
\text { identification of the crime } \\
\text { suspects and the deceased? }\end{array}$ & 15 & 85 & \\
\hline 7. & $\begin{array}{l}\text { Whether you have come } \\
\text { across the patients who } \\
\text { have been previously } \\
\text { treated by other dentist? }\end{array}$ & 98 & 2 & \\
\hline 8. & $\begin{array}{l}\text { If so, whether those } \\
\text { patients have proper } \\
\text { medical/dental record from } \\
\text { the previous practitioner? }\end{array}$ & 6 & 94 & \\
\hline 9 & $\begin{array}{l}\text { Do you think maintaining } \\
\text { records is necessary for } \\
\text { every visit/treatment } \\
\text { provided at your clinic/ } \\
\text { practice? }\end{array}$ & 68 & 32 & \\
\hline 10 & $\begin{array}{l}\text { Are you aware that a copy } \\
\text { of treatment record should } \\
\text { be given to patient, if asked } \\
\text { for? }\end{array}$ & 66 & 34 & \\
\hline 11 & $\begin{array}{l}\text { Are you aware that you can } \\
\text { present an expert testimo- } \\
\text { ny in the court supported } \\
\text { by dental records as an } \\
\text { evidence? }\end{array}$ & 6 & 94 & \\
\hline 12 & $\begin{array}{l}\text { Are you aware of any } \\
\text { course or have you } \\
\text { attended any workshop } \\
\text { related to medicolegal } \\
\text { issues? }\end{array}$ & 2 & 98 & \\
\hline 13 & $\begin{array}{l}\text { Do you know what } \\
\text { consumer protection } \\
\text { act is? }\end{array}$ & 80 & 20 & \\
\hline 14 & $\begin{array}{l}\text { Do you know the legal } \\
\text { procedures to tackle } \\
\text { consumer protection act? }\end{array}$ & 32 & 68 & \\
\hline 15 & $\begin{array}{l}\text { Do you think a dentist is } \\
\text { having all knowledge of } \\
\text { medical jurisprudence? }\end{array}$ & 8 & 92 & \\
\hline
\end{tabular}




\section{Discussion}

Dental jurisprudence, forensic odontology, and legal dentistry are considered synonymous to denote that branch of dentistry which treats of the application of the principles and knowledge of dentistry to the purpose of law; both civil and criminal. According to DCI Rule and regulation 2007, there will be 10-12 hours given for didactic lecture and 20-25 hours will be given for practical classes on forensic odontology. ${ }^{6}$ Forensic odontology should include a preclinical stream and clinical stream. The clinical stream will include maintaining dental records, medical jurisprudence, and ethics. ${ }^{6}$ In number of developed countries, odontolegal practice has gained a huge significances but still lacks in developing countries like India and requires a serious thrust. ${ }^{4}$ The owner of the dental practice is usually the legal owner of the records. These records should never be released by the dentist unless asked by the patient. ${ }^{7}$ There are several exceptions to this rule:

- When referring cases to another dentist either for consultation or for treatment.

- When demanded by the court in cases of medicolegal issues, occupation related, or road traffic accidents requiring compensation, the original record should be submitted. At the same time, it is essential to keep the photocopy of the same.

- On request of the police.

- When asked by income tax authorities or insurance companies. ${ }^{7}$

The study was carried out amongst the oral health practitioners to evaluate their awareness and knowledge about legal use of dental records. The results show that the knowledge and the awareness about the dental records and medical jurisprudence among the dental practitioners are not adequate. Nearly twothird of the respondents was unaware that dental records have a validity in the court of justice and they can present an expert testimony on basis of these records. ${ }^{4}$ It is also recommended by $\mathrm{DCl}$ that the dental graduate on completion of their BDS should be aware of ethical and legal responsibilities in their routine practice and should be able to analyze, evaluate, and present dental facts within the legal framework. But the truth is no dental graduate is having full knowledge of maintaining dental record and their importance. At the same time, no dental graduate is practising ethically with the knowledge of medical jurisprudence. Dental record serves as an important adjunct in malpractice litigation and it serves as the basis for the defence of negligence claims. Poorly maintained, incomplete, or altered dental records are questionable in the court of justice regarding the treatment given and the details of the patient. ${ }^{2}$ Proper documentation with accurate and completed medical and dental history reflecting the details of the patient creates a legal document. This study was carried out to determine the knowledge and awareness regarding medical jurisprudence. In the study, it is noticed that most of the dental practitioners have no knowledge and they had not experienced any medicolegal case during their course.
In the questionnaire, some of the dental practitioners have advised to develop a proper curriculum, which introduces the dental students to the knowledge of medical jurisprudence and to the medicolegal cases. ${ }^{3}$

\section{Conclusion}

This study was a sincere effort to gauge the knowledge and awareness of dental practitioners about odontolegal practice and their knowledge about significance of maintaining the dental record. This study emphasis that the oral health professionals lacked the knowledge and awareness about odontolegal aspects, which would make them aware about medical jurisprudence and therefore needs to be considered in the curriculum for dental students as this would avoid legal complications in their future practice. The working dental practitioners were also willing to acquire knowledge about medical jurisprudence by means of CDE (Continuing dental education) programs. With the increasing use of mediclaims, negligence suits, scientific evaluation, and research purposes, and health planning, etc., the "dental records itself have evolved as separate science." The hospital and doctor were supposed to be guilty of deficiency in service if dental records were not produced before the court of justice for any legal purpose.

\section{Acknowledgments}

The authors are thankful to all the dental practitioners for their participation and cooperation. A special thanks to the colleagues belonging to different states who directly or indirectly helped in distributing and collecting the questionnaire among the dental practitioners of their respective states. Their sincere thanks to the staff of all those dental colleges who with their continuous support helped us in achieving the results.

\section{References}

1. Charangowda BK. Dental records: an overview. J Forensic Dent Sci 2010;2(1):5-10. DOI: 10.4103/0974-2948.71050 PMC. Web. 26 Mar. 2017.

2. Waleed $\mathrm{P}, \mathrm{Baba} F$, Alsulami S, et al. Importance of dental records in forensic dental identification. Acta Inform Med 2015;23(1):49-52. DOI: 10.5455/aim.2015.23.49-52 PMC. Web. 26 Mar. 2017.

3. Venkat Rao G, Hari N. Medico-legal knowledge assessment of interns and post graduate students in a medical institution. IAIM 2016;3(10):105-110.

4. Preethi S, Einstein A, Sivapathasundharam B. Awareness of forensic odontology among dental practitioners in Chennai: a knowledge, attitude, practice study. J Forensic Dent Sci 2011;3(2):63-66. DOI: 10.4103/0975-1475.92145 PMC. Web. 26 Mar. 2017.

5. Gupta A, Mishra G, Bhutani H, et al. Forensic revolution need maintenance of dental records of patients by the dentists: a descriptive study. J Int Soc Preventive Community Dent 2016;6(4):316-320. DOI: 10.4103/2231-0762.186799. PMC. Web. 26 Mar. 2017.

6. http://dciindia.gov.in/Rule_Regulation/Revised_BDS_Course_ Regulation_2007.pdf.

7. Thomas J. Medical records and issues in negligence. Indian J Urol 2009;25(3):384-388. DOI:10.4103/0970-1591.56208. 